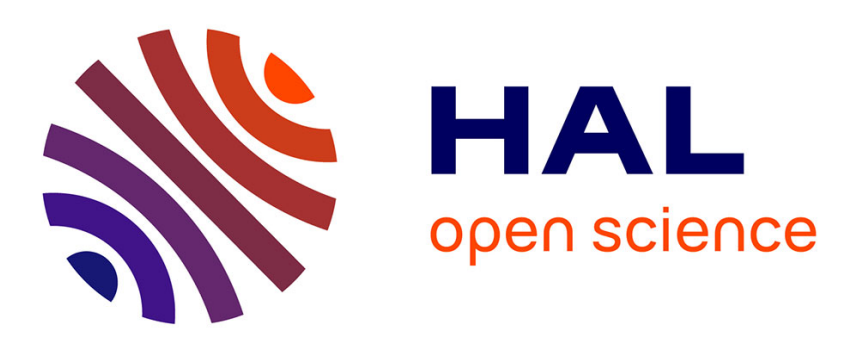

\title{
An innovative "zapping video" as a teaching aid: what effects on students? The case of a video put online by a training institute
}

Hélène Hoblingre Klein

\section{- To cite this version:}

Hélène Hoblingre Klein. An innovative "zapping video" as a teaching aid: what effects on students? The case of a video put online by a training institute. 13th International Conference of Education, Research and Innovation, Nov 2020, Valence (on line), Spain. hal-03410417

\section{HAL Id: hal-03410417 https://hal.science/hal-03410417}

Submitted on 3 Nov 2021

HAL is a multi-disciplinary open access archive for the deposit and dissemination of scientific research documents, whether they are published or not. The documents may come from teaching and research institutions in France or abroad, or from public or private research centers.
L'archive ouverte pluridisciplinaire HAL, est destinée au dépôt et à la diffusion de documents scientifiques de niveau recherche, publiés ou non, émanant des établissements d'enseignement et de recherche français ou étrangers, des laboratoires publics ou privés. 


\section{An innovative "zapping video" as a teaching aid: what effects on students?}

The case of a video put online by a training institute

The development of the use of ICT (information and communication technology) for education has gained new impetus in France with the health crisis of 2020 and the prescription of pedagogical continuity through the use of digital tools (Vilches et al., 2020). Educational technologies are thus definitively establishing themselves as a field of research for the future, and authors have taken an interest in the transformation of teaching and training through ICT (Henri \& Charlier, 2010), (Karsenti \& Bugmann, 2017). Indeed, the use of ICT for training requires, among other things, a change in pedagogical paradigm (Tessier, 2019) and a modification of practices in order to avoid falling into the trap of instrumental conflict or impoverishment of tools (Marquet, 2011).

Until now, researchers in Education Sciences have mainly focused on the effectiveness of videos used in teacher training. These are either self-confrontation videos or classroom videos. Researchers have also been interested in Moocs videos. They are therefore mainly videos integrated into training devices that have been studied for the moment. To complete this work, we will move on to pedagogical videos that are not part of a training system, that is to say, pedagogical videos that have an autonomous existence.

We have therefore chosen an innovative pedagogical video, published by a training institute, as the object of study here. This video does not fit into any training system and it explains what the job of UX designer consists in. It is published on the home page of a digital training institute's website.

In order to shed light on the practices related to the use of ICT for training, we propose a case study: here we analyze the pedagogical effects of this innovative video used by a recognized training institute. First, we wanted to understand why this video is truly innovative and we also wanted to understand the objectives of the training institute. Why does it publish such a video? Is the objective truly pedagogical? To answer these first questions, we have conducted 3-step research. First, we carried out a fine semiotic analysis of the video in order to understand its specificities. Then, we conducted a directive interview with the training institute in order to understand the origin and the objective pursued through this video. Finally, we conducted an experiment to understand the effect of the video on the students.

As far as scientifical references are concerned, we have approached this video both from a developmental and a communicational point of view, referring to professional development theorists (Lefeuvre et al., 2009) and attention theories (Citton, 2014). Since the video at the heart of our analysis is characterized by strong visual zapping, it also seems unavoidable to call upon the contributions of Hayles (2007) and Arbuthnott \& Frank (2000), relating to hyperattention and the "cost of the switch".

\section{Findings}

\section{An interview}

First of all, the interview allowed us to say that the school pursues 3 objectives throw the video. The first one: to help students acquire knowledge about a profession. It is a pedagogical objective. The second one: to orient students or future students professionally and to democratize the knowledge of professions for the greatest number. It is an objective of professional orientation. The third one: to make the school known. It is a marketing objective. 
In these purposes, the institute tried to entertain the spectator and make him laugh, in particular thanks to a quick sequence of images. What seems innovative here is this desire to reconcile very different objectives, and especially the ambition to reconcile marketing and pedagogy.

The video itself is also quite innovative. If you look at it from a teacher's point of view, its characteristics can be surprising. It is elaborated according to advertising and marketing techniques. And indeed, the video was made by a former student, working in the field of marketing and communication.

\section{A semiotic analysis}

The semiotic analysis of the video then led us to highlight the 4 characteristics of the video, which we call here "Zapping Video". Firstly, clips from commercials and television series have been integrated. Secondly, humorous situations punctuate the video. Thirdly, the images of the video follow one another extremely quickly: 53 clips (from advertisements, TV series and other unspecified media) follow one another in the span of 2.6 minutes. This means that each video segment lasts an average of 2.3 seconds. At the same time, the commentator's speech rate is quite fast. Fourthly, the editing is done "word for word", that is to say that a sentence segment, sometimes a word, is illustrated by a specific clip. For example, the sentence "The UX designer always works hand in hand with the graphic designers" will be illustrated by 3 clips. You can see their first image here.

To use Choplin's criterion, it can therefore be said that this video is innovative, in so far as it is based on a "new object". Moreover, it breaks with the codes of traditional teaching and even with certain theories of learning. Indeed, visual zapping promotes hyper-attention, whose negative effects on learning have already been demonstrated Moreover, this video is quite entertaining. The interviewee herself was aware of the innovative nature of this video: I quote her: "it's a new way of working. A few years ago, we didn't have that," she says.

On this basis, we can therefore formulate the following question: do the characteristics of the video make it possible to achieve the objectives pursued by the school? Can a video be at the same time at the service of marketing and pedagogy? That brings me to the formulation of my main research question: what are the qualities and directs of this pedagogical innovation in terms of learning?

\section{A questionnaire}

To answer this question, a large-scale questionnaire was submitted to respondents immediately after they viewed the video. This questionnaire was structured in 3 main parts in order to:

- Assess the level of comprehension (9 questions on the theoretical content were asked)

- To identify the 3 images (or clips) stored in priority

- Determine if these images (or clips) promote the memorization of the theoretical content

A total of 90 (ninety) individuals took part in the experiment, 26 years old on average, all levels and disciplines combined, from bachelor's degree to master.

Respondents are quite positive about the educational impact of this video. $67 \%$ consider that this video allows them to understand what a UX designer is. When the respondents' level of comprehension is then assessed, the results coincide perfectly with this first statement. Indeed, each participant answered 9 closed-ended questions to assess the lèvel of understanding and assimilation of the theoretical content. Out of the 86 participants, $66 \%$ of the answers were correct. The comprehension is therefore reasonable. Moreover, despite the zapping effect, $89 \%$ of participants retained 1 to 3 different images at least.

Moreover, this video is, in accordance with the wishes of the training institute, a playful learning support. When respondents were asked to rate the level of entertainment generated by the video, from 1 to 9, the level of entertainment was rather high.

Another quality of the video: It allows a good memorization of the images. $29 \%$ of respondents remember at least 3 extracts. 
However, these initial statistics remain to be qualified. Indeed, the questions requiring a more detailed understanding of the content, the 5 th and 4 th, are those that received the fewest correct answers. The didactic content was certainly understood, but in a very global way.

Moreover, the results show a relationship between memorization and the presence of marketing contents. Indeed, among the images that most struck the participants, advertising excerpts are at the top of the list. Images of unknown origin come next, followed by excerpts from television series.

Yet, the analysis also reveals certain pedagogical flows. Indeed, the original advertising message of some images is sometimes retained in priority. In this sense, the editing of the video, based on marketing techniques, can be an obstacle to learning.

We will take here an example that illustrates this phenomenon. One of the best memorized excerpts was memorized by 12 people. It is an excerpt from an advertisement for "Just eat". Through this excerpt, the aim was to show that the UX designer creates functional and ergonomic applications. However, among these 12 people, none of them was able to give the excerpts a meaning related to the didactic content of the video.

When I asked them what the meaning of this excerpt was, in the context of the video, five participants simply evoked the original marketing message of the advertising. One of the respondents, when asked about the meaning of this clip in the video wrote: "Ordering food is very simple, just go to an application and click. You don't have to cook any more". Another 11 respondents clearly tried to reconstruct the meaning of this image in the video, but without really succeeding. For example, one of them wrote, "You have to be up to date and be able to use the phone in a new way. »

\section{Conclusion}

Thanks to the semiotic analysis we suggested 4 criteria to identify what we call "video zapping". Under certain aspects, this video imposes itself as a pedagogical tool, for assimilating a knowledge and memorizing a content. Indeed, the viewer acquires new knowledge while having fun.

However, some subtleties of the didactic content were not understood. The comprehension is global, but this video is insufficient for getting deeper into the concepts.

The training institute is well aware of the pedagogical limits of this video. Let's quote the interviewee:

"You have to watch this video several times: the first time you get caught up in the dynamism and humor. Do we take into account the content? Maybe not... Once you've taken it under its humorous side, maybe you need to listen to it again, and then you've understood. ...] it's really a general view, and then you clarify things".

The pedagogical effectiveness of this video must therefore be questioned on two levels:

First, this video should be viewed several times and the viewing must be discussed afterwards with the teacher

Secondly, we consider that this video should not include excerpts from advertisements. On the one hand, the integration of advertisements raises an ethical question: do we have the right to address the student as a consumer? On the other hand, as we have shown, the integration of advertisements may have been detrimental to the memorization of the didactic content.

\section{BIBLIOGRAPHIE}

- Arbuthnott, K., \& Frank, J. (2000). Executive control in set switching: Residual switch cost and task-set inhibition. Canadian Journal of Experimental Psychology/Revue Canadienne de Psychologie Expérimentale, 54(1), 33-41. https://doi.org/10.1037/h0087328

- Citton, Y. (2014). Pour une écologie de l'attention. Le Seuil.

- Hayles, K. (2007). Hyper and Deep Attention: The Generational Divide in Cognitive Modes. Profession, 187-199.

- Henri, F., \& Charlier, B. (Eds.). (2010). Apprendre avec les technologies. Presses Universitaires de France.

- Karsenti, T., \& Bugmann, J. (Eds.). (2017). Enseigner et apprendre avec le numérique. Les 
Presses de l'Université de Montréal.

- Lefeuvre, G., Garcia, A., \& Namolovan, L. (2009). Les indicateurs de développement professionnel. Questions Vives. Recherches en éducation, 5(11), 277-314. https://doi.org/10.4000/questionsvives.627

- Marquet, P. (2011). E-Learning et conflit instrumental. Recherche et formation, 68, 31-46.

- Tessier, L. (2019). Eduquer au numérique? : Un changement de paradigme. MkF Editions.

- Vilches, V. A., Detroz, P., Hausman, M., \& Verpoorten, D. (2020). Réception de la prescription à «basculer vers l'eLearning» en période d'urgence sanitaire - Une étude de cas. e-JIREF, 1, 5-16. 